\title{
Rethinking the ethics of ventricular assist device withdrawal
}

\author{
John W. C. Entwistle, MD, PhD, ${ }^{a}$ and Kathleen N. Fenton, MD, MS ${ }^{\mathrm{b}}$

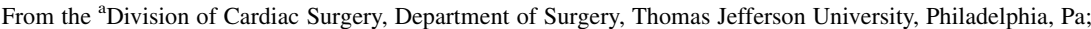 \\ and ${ }^{\mathrm{b}}$ The William Novick Cardiac Alliance, Memphis, Tenn. \\ Received for publication May 12, 2019; revisions received June 17, 2019; accepted for publication June 23, 2019 ; \\ available ahead of print Dec 4, 2019. \\ Address for reprints: John W. C. Entwistle, MD, PhD, 1025 Walnut St, Suite 607, College Building, Philadelphia, \\ PA 19107 (E-mail: john.entwistle@jefferson.edu). \\ J Thorac Cardiovasc Surg 2020;159:1328-32 \\ $0022-5223 / \$ 36.00$ \\ Copyright (C) 2019 Published by Elsevier Inc. on behalf of The American Association for Thoracic Surgery \\ https://doi.org/10.1016/j.jtcvs.2019.06.130
}

Ventricular assist devices (VADs) have revolutionized the care of patients with heart failure. As an end-of-life act, withdrawal usually follows a life-threatening illness or device complication. Infrequently, a patient who has grown tired of life ("existential suffering") requests withdrawal to hasten death. Existential suffering (demoralization), often described as angst, is different from depression with suicidal ideation, although the two can coexist. ${ }^{1}$ The presence of depression, a clinical syndrome with specific diagnostic criteria, requires treatment of the mental illness before discontinuation of any medical therapy. Requests for VAD withdrawal in existential suffering are uncommon and can be the source of moral distress for care providers, patients, and families involved. VAD withdrawal in existential suffering is ethically distinct from the previous scenarios. Should such patients be allowed to request VAD withdrawal, and can a medical professional be pressured into complying with these wishes?

Modern long-term VADs bear little resemblance to earlier devices. Newer VADs can provide a decade or more of survival, are less intrusive, and have low complication rates. Survival is approaching that of heart transplantation. Although still artificial devices, VADs now resemble transplanted organs in that they are implanted within the body and become an integrated part of the patient. ${ }^{2}$ These changes in function and outcome necessitate reconsideration of the ethical aspects of VAD use and become increasingly relevant when end-of-life options are discussed with patients. $^{3,4}$

\section{WITHDRAWAL OF VAD SUPPORT IN THE ABSENCE OF A MAJOR COMPLICATION}

Under the principle of autonomy, a person with capacity may refuse medical care, including VAD therapy, even if this results in premature death. However, there is a dichotomy in attitudes regarding VAD withdrawal among VAD professionals. Among VAD cardiologists, 43\% maintained that VAD withdrawal is inappropriate in a patient who is not

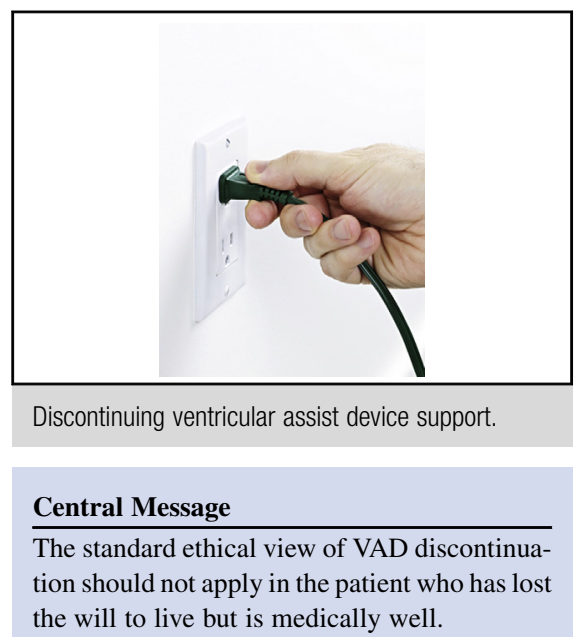

nearing death, whereas this view was shared by only $12 \%$ of hospice and palliative care physicians. ${ }^{5}$ Similarly, $60 \%$ of heart failure specialists felt that a patient needed to be dying to justify discontinuation of VAD support, and $43 \%$ felt that a request for VAD discontinuation should never be honored if the patient is not nearing death. ${ }^{6}$

Two features of modern VADs impact the applicability of the established ethical views to the patient with a VAD with existential suffering. First and foremost, physiological changes produced by modern VADs fundamentally alter the manner in which the prevailing ethical approach to these patients is considered. Second, modern VADs require an external power source and electrical controller, and patients and their support teams are fully capable of interacting with these devices on a daily basis, making the involvement of the medical community in withdrawal of support unnecessary.

\section{THE ALTERED PHYSIOLOGY OF MODERN VADS}

Earlier VADs contained valves that prevented blood flow in the reverse direction through an unpowered pump. These pulsatile pumps become irrelevant if turned off, as the patient is supported by their native heart with a resultant physiology similar to that present before VAD insertion. Modern VADs are continuous-flow (cfVAD) devices, and neither require nor are compatible with internal valves. Unlike their predecessors, if a cfVAD loses power, the patient experiences a state similar to acute aortic valve insufficiency. Without forward flow produced by the VAD, and no valve 
to prevent retrograde flow, blood flows down the pressure gradient from the aorta to the left ventricle through the VAD during diastole. ${ }^{7}$ Deactivation of a cfVAD creates a non-physiologic situation, with the potential to accelerate death due to the additional stress placed on an alreadyweakened heart. In one study, 3 of 4 patients with a driveline disconnection required cardiopulmonary resuscitation. ${ }^{8}$ Since most durable VAD implantations are done when a patient is reasonably stable, discontinuation of support most likely accelerated their decompensation due to the altered physiology produced by the inactive, valve-less pump. A new, potentially lethal pathology has been created by the cfVAD.

Some argue that death in VAD withdrawal is still due to the underlying heart failure, ${ }^{9}$ but this ignores the regurgitation occurring through the deactivated pump. Since death is expected quicker with deactivation than expected by the natural course of the underlying disease, deactivation of the device is inappropriate. ${ }^{10}$ In the case of cfVADs, death after deactivation is due to the severe regurgitant flow through the VAD cannula and not directly from the underlying heart failure. Thus, only occlusion of the cfVAD outflow graft to eliminate the non-physiological condition before VAD discontinuation could be argued as allowing nature to take its course.

\section{THE ROLE OF THE PATIENT AND FAMILY IN THE DISCONTINUATION OF VAD SUPPORT}

Long-term VADs are designed for home use. VADs are powered by rechargeable batteries via a small controller. Patients and families are taught to care for this equipment. If power is lost, the VAD will turn off. While the patient and support team keep the VAD running, they have the unique potential to turn the device off without any outside intervention. Thus, a patient with a VAD who is unhappy with life has the capability to discontinue support without any external involvement of health care providers.

\section{THE RIGHT TO WITHDRAW CARE AND DUTY}

Withdrawal of care is generally regarded as a patient right under the auspices of autonomy. If (but only if) this requires action by the medical team, then the expression of autonomy by the patient places a duty on the medical team.

In VAD withdrawal, involvement by the medical team may be desired by the patient or family, but it is not necessary. The external power supply provides the patient and caregivers with the ultimate control in determining if and when to withdraw support. A patient with existential suffering can cease VAD support at any time by failing to recharge the batteries or by disconnecting the VAD from its controller. Thus, the patient with existential suffering can exert their right to stop VAD therapy without inflicting a duty upon any medical professional.

\section{"ALLOWING TO DIE" VERSUS "KILLING," AND THE WITHDRAWAL OF VAD SUPPORT}

The right of a person to refuse medical therapy and hasten death is generally accepted under the auspices of autonomy in many cultures. Withdrawal is commonly seen in end-oflife scenarios with futile care, so the patient is "allowed to die" of the underlying condition. According to Sulmasy, ${ }^{11}$ "allowing to die" occurs when death results from a preexisting fatal condition, whereas "killing" occurs when a new lethal physiologic condition is created. Injection of potassium to produce cardiac arrest is a new lethal physiologic condition, unlike removal of an endotracheal tube in a patient who is ventilator dependent. While both will lead to the same outcome (death) and may relieve suffering, only the latter is generally considered ethically justified, as the cause of death is the underlying condition. Although some consider "killing" and "allowing to die" as morally equivalent, even if legally different, such that if one is morally permissible, then both should be, ${ }^{12}$ we maintain that the cause of death (action vs underlying disease) is important in the morality of the process.

Withdrawal of VAD support in a patient who has suffered a major complication respects autonomy, as the patient dies of the complication. However, the same justification is often used in existential suffering. We argue that in this scenario, withdrawal of VAD support may be seen to be closer to "killing" than "allowing to die" for several reasons.

When a patient is doing well on VAD support, the severe congestive heart failure that necessitated VAD insertion is no longer a terminal disease. While cardiomyopathy may persist, their prognosis is markedly improved compared with their pre-VAD condition as long as the VAD is functioning. These patients often have years to live, free from the burdens of end-stage congestive heart failure that were present before VAD implantation. Second, as noted previously, the act of VAD implantation has created a new lethal physiology that was not present before VAD implantation, namely acute regurgitation through the disconnected VAD. Withdrawal of VAD support will lead to the hastened death of the patient through a new and lethal physiologic condition. This would be "killing," under the definition provided by Sulmasy. ${ }^{11}$

\section{INTENT OF WITHDRAWAL}

The intent of the action matters in the ethical analysis of withdrawal. In the patient with existential suffering, the intent of withdrawal is death. The purpose of an action cannot be to end the life of a patient. ${ }^{10}$ According to the doctrine of double effect, ${ }^{13}$ an action that leads to death as a result of trying to achieve a greater good is often ethically permissible. For example, the death caused by high doses of morphine to relieve pain in a terminal patient is ethically appropriate if the goal is to relieve the pain. In the case of a 
patient who no longer wants to live on VAD support, the action of VAD withdrawal will predictably cause the death of the patient, and death is the only manner to achieve the patient's perceived goal-violations of the doctrine of double effect.

\section{PERSISTENCE OF LEGAL ARGUMENTS}

Court cases are often cited to support the primacy of autonomy in discussions on VAD withdrawal. Several court cases have affirmed the patient's autonomy to refuse or discontinue treatment. Using this legal precedent, there is a persistent theme in the literature that a patient may demand VAD withdrawal under the auspices of autonomy whenever the device is considered onerous to the patient, when the perceived burden of the device exceeds the perceived benefit, or if therapy with the device is no longer desired. ${ }^{5,7,14,15}$ Although none of these cases addressed a problem similar to VAD withdrawal in the case of existential suffering, they have at times been applied here.

The right to refuse care, even that already initiated, is supported by case law. Table 1 shows several cases that have established and confirmed this right. In both Quinlan and Cruzan, 2 cases of young women in a persistent vegetative state, the right of the patient placed a duty on the medical professionals to remove support because the requested actions were impossible for the patient to perform. However, although a patient has a right to refuse treatment or have existing treatment withdrawn, there have been no cases (to the best of our knowledge) in which a medical professional has been compelled to directly end a patient's life through action when the patient is mentally and physically capable of performing the same action. Further, the Quill and Glucksberg cases, both brought to fight the prohibition against assisted suicide, demonstrated that there is a legal difference between "killing" and "allowing to die," respect for bodily autonomy does not extend to the point of hastening death, and that there is no inherent right to assistance in dying. Thus, citing legal precedent as justification for VAD withdrawal in existential suffering is a gross oversimplification of the cases, as they have limited applicability to the situation at hand.

\section{WITHDRAWAL OF VAD SUPPORT AND SUICIDE}

Physician-assisted suicide (PAS) refers to the indirect involvement of a physician in the elective termination of a patient's life through the direct actions of the patient, often through the provision of a prescription for medications that are taken by the patient at a lethal dose. PAS laws are active in Oregon, Washington, Vermont, California, Washington, DC, Colorado, and Hawaii. In addition, PAS is permissible in Montana through a court order. Where PAS is legal, there is the requirement for a terminal illness with death expected, generally within 6 months. An appropriate medical and/or psychological evaluation is required. There is a

TABLE 1. Court cases

\begin{tabular}{|c|c|c|c|c|}
\hline Court case/individual(s) & Condition of person(s) & Aim & Court & Pertinent finding(s) \\
\hline $\begin{array}{l}\text { In re Quinlan } \\
\text { Karen Ann Quinlan }\end{array}$ & $\begin{array}{l}\text { Persistent vegetative } \\
\text { state }\end{array}$ & Disconnection of ventilator & $\begin{array}{l}\text { Supreme Court of New } \\
\text { Jersey }\end{array}$ & $\begin{array}{l}\text { Right to privacy permits } \\
\text { right to refuse medical } \\
\text { care }\end{array}$ \\
\hline $\begin{array}{l}\text { Cruzan v. Director, Missouri } \\
\text { Department of Health } \\
\text { Nancy Cruzan }\end{array}$ & $\begin{array}{l}\text { Persistent vegetative } \\
\text { state }\end{array}$ & Removal of feeding tube & $\begin{array}{l}\text { Supreme Court of the } \\
\text { United States }\end{array}$ & $\begin{array}{l}\text { Right of a competent person } \\
\text { to refuse medical care }\end{array}$ \\
\hline $\begin{array}{l}\text { Bouvia v. Superior Court } \\
\text { Elizabeth Bouvia }\end{array}$ & Cerebral palsy & $\begin{array}{l}\text { Permit patient to refuse } \\
\text { nutrition }\end{array}$ & California Court of Appeal & $\begin{array}{l}\text { Right to refuse force- } \\
\text { feeding even if not } \\
\text { terminally ill }\end{array}$ \\
\hline $\begin{array}{l}\text { Georgia v. McAfee } \\
\text { Larry McAfee }\end{array}$ & Quadriplegia & Disconnection of ventilator & Supreme Court of Georgia & $\begin{array}{l}\text { Right to refuse treatment in } \\
\text { the absence of a } \\
\text { compelling state interest }\end{array}$ \\
\hline David Rivlin & Quadriplegia & Disconnection of ventilator & $\begin{array}{l}\text { Oakland County Circuit } \\
\text { Court (Michigan) }\end{array}$ & Right to refuse treatment \\
\hline Vacco v Quill & Terminal illness & $\begin{array}{l}\text { Right to authorize a doctor } \\
\text { to end one's life }\end{array}$ & $\begin{array}{l}\text { Supreme Court of the } \\
\text { United States }\end{array}$ & $\begin{array}{l}\text { (1) No federal constitutional } \\
\text { right to assisted dying } \\
\text { (2) "No one is permitted to } \\
\text { assist a suicide" } \\
\text { (3) Intent in action is } \\
\text { important }\end{array}$ \\
\hline Washington v Glucksberg & Terminal illness & $\begin{array}{l}\text { Right to commit suicide } \\
\text { with assistance of another }\end{array}$ & $\begin{array}{l}\text { Supreme Court of the } \\
\text { United States }\end{array}$ & $\begin{array}{l}\text { Right to assisted suicide is } \\
\text { not protected under due } \\
\text { process }\end{array}$ \\
\hline
\end{tabular}


waiting period, either defined or inherent in the process. Physicians may decline participation in the process. Finally, there is a requirement that the final action occur through the hands of the patient and not the medical provider. When the medical provider is physically involved in the dying act taken to relieve pain and suffering, that is commonly termed voluntary active euthanasia (VAE), currently only legal is a few countries and nowhere in the United States. Where legal, PAS protects the physician and patient from legal repercussions. Legal protection, however, does not mean, a priori, that an act is ethical, just as it can be said that an ethical act is not always legal.

A physician who disconnects a VAD from a patient who is medically doing well yet no longer wants to live is a participant in VAE, a form of "killing." These patients do not have a terminal illness, a requirement for PAS where legal in the United States. In the trial of the HeartMate II left ventricular assist device, ${ }^{16}$ the yearly mortality after initial recovery was 10 percentage points. Similar data have been seen repeatedly in the years since. It is a reasonable to estimate that the average survival of a patient on VAD support is better measured in years rather than months, indicating that this is not a terminal condition.

Second, and most importantly, PAS requires that the act that leads to dying be done by the patient. The patient may have the desire for the physician to disconnect the batteries, as this may be more morally palatable for the patient, but it is clearly not PAS as defined.

For the patient with a VAD with existential suffering, the easiest approach, and one that is available at all times and in all jurisdictions, is for the patient to disconnect the power supply and/or controller themselves, or fail to recharge the batteries. It would be similar to a patient who no longer goes to dialysis, stops taking life-saving medications, or refuses further chemotherapy. This passive approach to ending VAD support should not be viewed any differently from other cases of refusal. It would be reasonable for a patient to request legally prescribed medications to ease the pain or anxiety associated with this process.

In areas where PAS is legal, the patient with a VAD with existential suffering does not have a terminal illness and thus would not meet criteria for PAS. Health care provider involvement in these cases would be illegal. In areas where euthanasia is permissible, direct physician involvement in the process would be legal as long as the patient meets all other legal requirements. From the ethical standpoint, it should still be considered as "killing" in the form of VAE and its appropriateness subject to the debate surrounding this topic.

\section{CONCLUSIONS}

Withdrawal of VAD support in a patient who has suffered a major complication, and thus has a projected significant decrease in either quality or length of life, is reasonable under the auspices of autonomy. When a patient is doing well medically but choses to end their life through withdrawal of VAD support, this produces ethical and legal problems. From the ethical standpoint, it is more akin to "killing" than "allowing to die," since VAD implantation has created an abnormal physiology that would result in the equivalent of severe aortic valve insufficiency, hastening death more than that expected from heart failure alone. Demanding involvement of the medical community in the process also imposes a duty on the health care provider to satisfy the perceived needs of the patient.

From a legal standpoint, a patient who is doing well from a medical standpoint would not meet the criteria for PAS, as there is no terminal condition. Direct involvement of the medical professional in an act intended to end life would be VAE, and would be classified ethically as "killing." When a patient is doing well medically, yet desires VAD withdrawal, the patient may take an active or passive approach to achieve their goal. As the patient has complete control over the situation and does not need to involve the medical community, it removes the imposition of a duty on the health care providers for the patient to achieve their intended aim.

\section{Conflict of Interest Statement}

Authors have nothing to disclose with regard to commercial support.

\section{References}

1. Robinson S, Kissane DW, Brooker J, Burney S. A review of the construct of demoralization: history, definitions, and future directions for palliative care Am J Hosp Palliat Care. 2016;33:93-101.

2. Simon JR. Case study. "Doctor, will you turn off my LVAD?" Commentary. Hastings Cent Rep. 2008;38:14-5.

3. Entwistle JWC, Sade RM, Petrucci RJ. The ethics of mechanical circulatory support: the need for new guidelines. Ann Thorac Surg. 2012;92:1939-42.

4. Petrucci RJ, Benish LA, Carrow BL, Prato L, Hankins SR, Eisen HJ, et al. Ethical considerations for ventricular assist device support: a 10-point model. ASAIO J. 2011;57:268-73.

5. McIlvennan CK, Wordingham SE, Allen LA, Matlock DD, Jones J, Dunlay SM, et al. Deactivation of left ventricular assist devices: differing perspectives of cardiology and hospice/palliative medicine clinicians. J Card Fail. 2017;23:708-12.

6. Swetz KM, Cook KE, Ottenberg AL, Chang N, Mueller PS. Clinicians' attitudes regarding withdrawal of left ventricular assist devices in patients approaching the end of life. Eur J Heart Fail. 2013;15:1262-6.

7. Mueller PS, Swetz KM, Freeman MR, Carter KA, Crowley ME, Severson CJ, et al. Ethical analysis of withdrawing ventricular assist device support. Mayo Clin Proc. 2010;85:791-7.

8. Ahmed RA, Pizanis N, Koch A, Carstens H, Rassaf T, Ludike P, et al. Survival analysis and postoperative complications after ventricular assist device implantation; prognostic value of INTERMACS scale. Ann Cardiovasc Thorac Surg. 2018;1:15-23.

9. Bruce CR, Brody B, Majumder MA. Ethical dilemmas surrounding the use of ventricular assist devices in supporting patients with end-stage organ dysfunction. Methodist Debakey Cardiovasc J. 2013;9:11-4.

10. Bramstedt KA, Wenger NS. When withdrawal of life-sustaining care does more than allow death to take its course: the dilemma of left ventricular assist devices. J Heart Lung Transplant. 2001;20:544-8.

11. Sulmasy DP. Killing and allowing to die: another look. J Law Med Ethics. 1998; 26:55-64. 
12. Rachels J. Active and passive euthanasia. In: Rachels J, ed. Can Ethics Provide Answers? And Other Essays in Moral Philosophy. Lanham, MD: Rowman \& Littlefield Publishers, Inc; 1997:69-80.

13. Gillon R. The principle of double effect and medical ethics. BMJ. 1986;292:193-4

14. Wiegand DL, Kalowes PG. Withdrawal of cardiac medications and devices. AACN Adv Crit Care. 2007;18:415-25.
15. Chamsi-Pasha H, Chamsi-Pasha MA, Albar MA. Ethical challenges of deactivation of cardiac devices in advanced heart failure. Curr Heart Fail Rep. 2014;11: $119-25$.

16. Slaughter MS, Rogers JG, Milano CA, Russell SD, Conte JV, Feldman D, et al. Advanced heart failure treated with continuous-flow left ventricular assist device. N Engl J Med. 2009;361:2241-51. 